\title{
Hospital readmissions following initiation of nebulized arformoterol tartrate or nebulized short-acting beta-agonists among inpatients treated for COPD
}

\author{
This article was published in the following Dove Press journal: \\ International journal of COPD \\ 5 December 2013 \\ Number of times this article has been viewed
}

\author{
Vamsi Bollu' \\ Frank R Ernst ${ }^{2}$ \\ John Karafilidis' \\ Krithika Rajagopalan' \\ Scott B Robinson ${ }^{2}$ \\ Sidney S Braman ${ }^{3}$ \\ 'Sunovion Pharmaceuticals, Inc., \\ Marlborough, MA, ${ }^{2}$ Premier healthcare \\ alliance, Charlotte, NC, ${ }^{3}$ The Icahn \\ School of Medicine at Mount Sinai, \\ New York, NY, USA
}

\begin{abstract}
Background: Inpatient admissions for chronic obstructive pulmonary disease (COPD) represent a significant economic burden, accounting for over half of direct medical costs. Reducing 30-day readmissions could save health care resources while improving patient care. Recently, the Patient Protection and Affordable Care Act authorized reduced Medicare payments to hospitals with excess readmissions for acute myocardial infarction, heart failure, and pneumonia. Starting in October 2014, hospitals will also be penalized for excess COPD readmissions. This retrospective database study investigated whether use of arformoterol, a nebulized long-acting beta agonist, during an inpatient admission, had different 30-day all-cause readmission rates compared with treatment using nebulized short-acting beta agonists (SABAs, albuterol, or levalbuterol).
\end{abstract}

Methods: A US nationally representative hospital database was used to study adults aged $\geq 40$ years, discharged between January, 2006 and March, 2010, and with a diagnosis of COPD. Patients receiving arformoterol on $\geq 80 \%$ of days following treatment initiation were compared with patients receiving a nebulized SABA during hospitalization. Arformoterol and nebulized SABA patients were matched (1:2) for age, sex, severity of inpatient admission, and primary/secondary COPD diagnosis. Logistic regression compared the odds of readmission while adjusting for age, sex, race, admission type, severity, primary/secondary diagnosis, other respiratory medication use, respiratory therapy use, oxygen use, hospital size, and teaching status.

Results: This retrospective study compared 812 arformoterol patients and 1,651 nebulized SABA patients who were discharged from their initial COPD hospital admission. An intensive care unit stay was more common among arformoterol patients $(32.1 \%$ versus $18.4 \%, P<0.001)$, suggesting more severe symptoms during the initial admission. The observed readmission rate was significantly lower for arformoterol patients than for nebulized SABA patients $(8.7 \%$ versus $11.9 \%, P=0.017$ ), as were the adjusted odds of readmission (odds ratio $0.69,95 \%$ confidence interval 0.51-0.92).

Conclusion: All-cause 30-day readmission rates were significantly lower for arformoterol patients than nebulized SABA patients, both before and after adjusting for patient and hospital characteristics.

Keywords: patient readmission, case-control studies, adrenergic $\beta_{2}$ receptor agonists, comparative effectiveness research

\section{Introduction}

Chronic obstructive pulmonary disease (COPD) is a leading cause of morbidity and mortality. The worldwide prevalence of COPD, estimated at 7.6\%, increases with age to $9.9 \%$ in those aged 40 years or older and $14.2 \%$ in those aged 65 years or older. ${ }^{1}$ 
In high-income countries, the World Health Organization has identified COPD as the seventh leading cause of disabilityadjusted life years and the fourth global leading cause of death. ${ }^{2}$ In the US, chronic lower respiratory tract diseases, such as COPD, have been identified as the third leading cause of death. ${ }^{3}$ However, the mortality associated with COPD may be underestimated because the cause of death for individuals with COPD is often attributed to one of the common associated comorbidities. ${ }^{4}$

COPD imposes a substantial economic burden on the health care system. In 2008 , the US spent $\$ 53.7$ billion on direct health care costs for treating asthma and COPD. ${ }^{3}$ Average annual health care costs for COPD patients varied dramatically from $\$ 2,003$ to $\$ 43,471$ depending on the types of medical services utilized, with hospitalized patients requiring treatment in the intensive care unit incurring the greatest expense. ${ }^{5}$ Across all COPD patients, hospital admissions account for the majority $(>50 \%)$ of direct health care costs. ${ }^{5-7}$

The course of COPD is characterized by a slow, progressive deterioration in airflow that is punctuated by exacerbations and eventually may lead to severe disability or death. Many of the exacerbations can be treated on an outpatient basis, but more severe exacerbations may require hospitalization. Lung function generally declines after each exacerbation, particularly for those requiring admission to hospital. ${ }^{8}$ A recent large-scale naturalistic study of COPD found that the risk of readmission or death increased threefold after the first hospital readmission, and grew progressively to a 25 -fold increase following the tenth readmission. ${ }^{9}$ The risk for readmission was particularly elevated during the 3 months following discharge from hospital. ${ }^{9}$ Reducing readmissions through more effective treatment and disease management could potentially reduce treatment costs and slow disease progression in COPD.

In the US, Medicare is a federal insurance program funded through the Social Security system that provides health care coverage for individuals who are aged 65 years and older or who are permanently disabled. The program is administered by the Centers for Medicare \& Medicaid Services (CMS), a component of the Department of Health and Human Services. Among US Medicare beneficiaries who were hospitalized for COPD, nearly one in four $(22.6 \%)$ were readmitted within 30 days. ${ }^{10}$ Due to high rates of 30-day readmissions for US Medicare beneficiaries, the Patient Protection and Affordable Care Act of 2010 authorized the CMS to reduce payments to hospitals with higher than expected 30-day readmission rates for select conditions. ${ }^{11,12}$ Currently, heart failure, acute myocardial infarction, and pneumonia are targeted, ${ }^{13}$ but beginning in the fall of 2014, COPD will be added to the list of conditions. ${ }^{11,12}$

The interest in 30-day readmission rates is growing. The Journal of the American Medical Association recently published a special issue on this topic, including research that reviewed the diagnoses, timing, and demographics associated with the currently targeted 30-day readmissions, ${ }^{14}$ and the outcomes from a CMS-sponsored quality improvement program that showed a modest reduction of 0.56 readmissions per 1,000 beneficiaries per quarter in the intervention communities (where hospitals implemented care transition interventions, medication management improvements, and standardization of the discharge planning process) relative to the control communities. ${ }^{15}$

The Global initiative for chronic Obstructive Lung Disease (GOLD) guidelines recommend maintenance therapy using long-acting bronchodilators for all patients who require continuous bronchodilation because of frequent daily symptoms. ${ }^{16}$ However, despite these treatment recommendations, short-acting bronchodilators are used alone in usual clinical care for $20 \%$ of patients with moderate COPD. ${ }^{17}$ Short-acting bronchodilators, on the other hand, are recommended for use as rescue medications or to treat the intermittent symptoms for patients with early-stage COPD.${ }^{16}$ Because of the advantages of using long-acting bronchodilators in patients with more advanced disease, the use of the these agents in patients hospitalized with an exacerbation of COPD may represent a potential approach for reducing 30-day readmission rates and, consequently, overall readmission rates. ${ }^{18}$

The purpose of this retrospective study was to examine 30-day readmission rates for patients treated with either nebulized arformoterol or a short-acting $\beta_{2}$ agonist (SABA) bronchodilator during a hospitalization for COPD. In general, long-acting $\beta_{2}$ agonists (LABAs) can be delivered via a metered-dose inhaler, dry powder inhaler, or nebulizer. Nebulized administration may have several advantages. For example, it may yield a more consistent medication dose due to fewer user errors, especially in older patients with COPD, and many patients prefer to use nebulizers over metered-dose inhalers and dry-powder inhalers. ${ }^{19,20}$ In view of these potential advantages, we hypothesized that arformoterol, a LABA medication delivered via a nebulizer, would result in fewer hospital readmissions within 30 days than a nebulized SABA, when used in similar hospitalized patients with COPD who were subsequently discharged. The objective of this retrospective study was to compare all-cause 30-day readmission rates, subsequent to an initial inpatient stay, among matched COPD patients who were treated with 
nebulized arformoterol or a nebulized SABA (at least $80 \%$ of the time spent in hospital, in order to simulate use once the patient was admitted) during the initial hospital stay.

\section{Materials and methods Study design}

This retrospective administrative database study used a matched case-control design. The administrative hospital data were from the database maintained by Premier, Inc. (Charlotte, NC, USA), the largest hospital-based, servicelevel database in the US. The database contained detailed service information from over 500 hospitals and more than 50 million inpatient discharges since 2000. It was nationally representative of hospital coverage by number of beds, US census region, urban setting, and teaching status. The database did not include any identifiable protected health information and, pursuant to the Health Insurance Portability and Accountability Act of 1996, the study did not require institutional review board waiver or approval. ${ }^{21}$

\section{Inclusion and exclusion criteria}

This retrospective study included patients who were at least 40 years of age when they were initially admitted to the hospital between January 1, 2006 and March 31, 2010. All patients were required to have either a primary discharge diagnosis for COPD (ICD-9-CM codes 491.xx, 492.xx, or 496.xx) or a secondary diagnosis for COPD along with a primary discharge diagnosis for another respiratory condition (ICD-9-CM codes 460.xx-519.xx). Patients in the primary treatment cohort were required to initiate arformoterol treatment and receive arformoterol for at least $80 \%$ of the inpatient days following initiation. The comparison cohort was comprised of patients who were treated with a nebulized SABA (either albuterol or levalbuterol) on each day during admission and who did not receive any nebulized LABA treatment. The arformoterol patients could have been treated with a SABA prior to and after initiating arformoterol. Patients were excluded if they died during the initial admission. Figure 1 shows the patient flow through the inclusion and exclusion criteria.

\section{Outcomes measure}

The primary outcome variable was 30-day all-cause readmission. It was operationally defined as readmission to the same hospital within 30 days of the discharge date.

\section{Matching procedure}

Retrospective studies that effectively control for selection bias have a high degree of validity. Selection bias could have occurred in this study if the patients treated with arformoterol systematically differed from those treated with a nebulized SABA on background characteristics that were associated with the risk of 30-day readmission. All background characteristics were identified from information collected during the initial hospitalization, prior to assessing 30-day all-cause readmission.

Demographic characteristics that were controlled for in the analysis included age, sex, and race, given that the risk of hospital admissions has been associated with age and other demographic characteristics. ${ }^{10,22}$ The analysis also controlled for characteristics of the hospital, including geographic location, urban or rural setting, teaching status, and total number of beds, because the likelihood of readmission has been shown to vary by hospital and hospital characteristics such as geographic location and size. ${ }^{10}$

Clinical characteristics from the initial hospitalization that were controlled for included primary versus secondary COPD diagnosis, admission type (emergency room versus other), length of stay, and severity. Disease progression and severity have been closely linked to the risk of readmission. ${ }^{9}$ Severity was assessed using the $3 \mathrm{M}^{\mathrm{TM}}$ All Patient Refined ${ }^{\mathrm{TM}}$ Diagnosis-Related Groups (APR-DRG) severity of illness classes. ${ }^{23}$ These severity of illness classes range from 1 (mild) to 4 (extreme) and are based on age, primary and secondary diagnoses, and certain procedures performed during hospitalization. ${ }^{23}$ Finally, the analysis controlled for other treatments that were administered during the initial admission, including oxygen therapy, respiratory therapy, anticholinergic treatment, corticosteroid treatment, antibiotic treatment, and other COPD medications. The concomitant treatments could have directly affected readmission, but could also reflect important differences in case complexity.

In part, because there were more nebulized SABA patients in the data, and to develop more similar cohorts for comparison, each patient treated with arformoterol was matched to two patients treated with a nebulized SABA. Exact matches were made on age, sex, APR-DRG severity of illness, and primary versus secondary COPD diagnosis. Matches were made prior to excluding patients who died during the baseline admission. All of the other background characteristics described above were statistically controlled in the data analyses.

\section{Statistical methods}

Descriptive statistics included means and standard deviations for continuous measures and number and percentage of patients for categorical measures. Unadjusted differences 


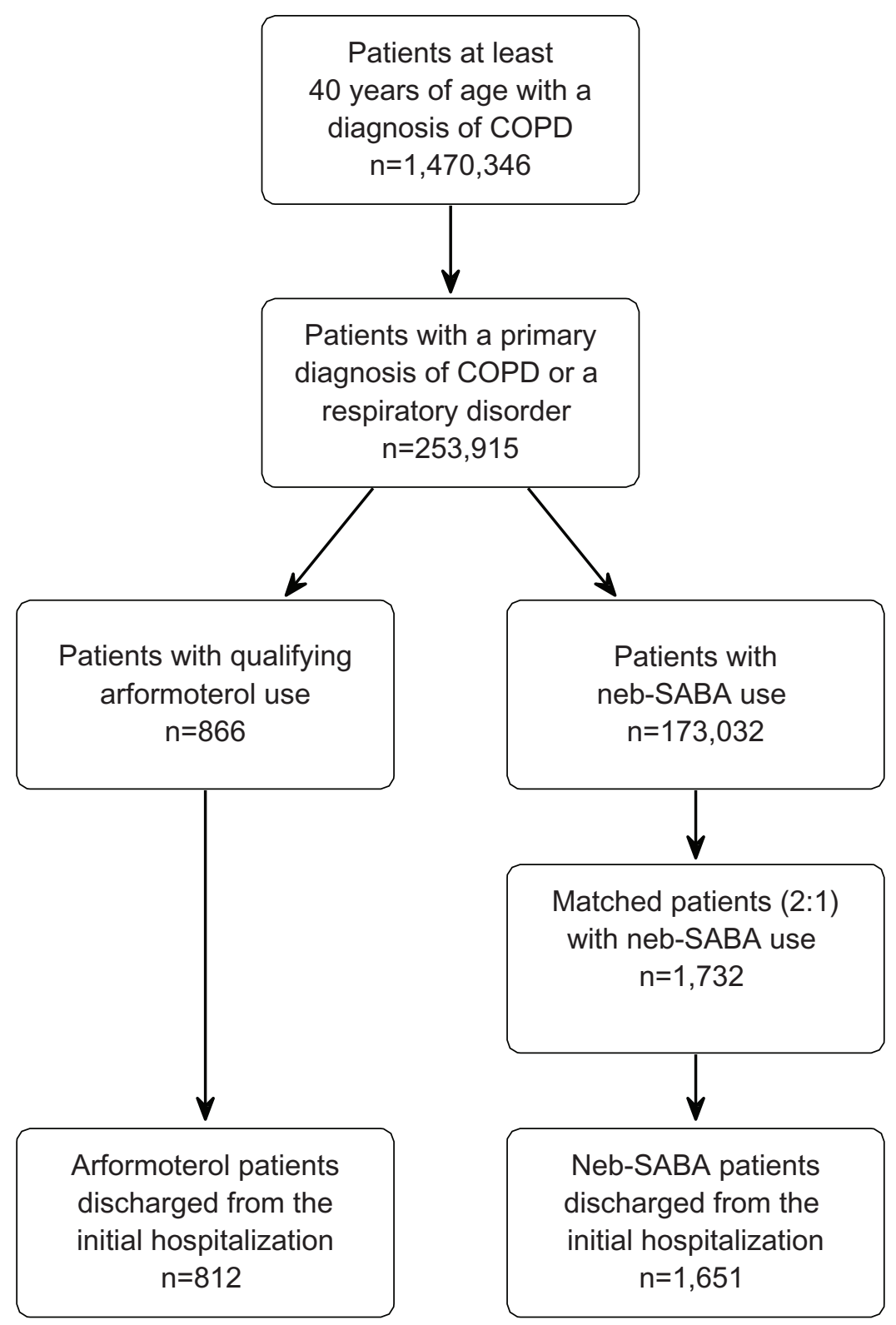

Figure I Patient flow through the inclusion and exclusion criteria.

Abbreviations: COPD, chronic obstructive pulmonary disease; neb-SABA, nebulized short-acting $\beta_{2}$ agonist.

between patients treated with arformoterol or a nebulized SABA during the initial admission were assessed using $t$-tests for continuous measures and chi-square tests for categorical variables.

The adjusted odds of being readmitted in 30 days were assessed using multivariate logistic regression. The regression analysis compared this primary outcome between the arformoterol patients and nebulized SABA patients while statistically adjusting for the previously described set of variables. The two-tailed alpha level was set to 0.05 and all analyses were completed using SAS version 9.2 (SAS Inc,
Cary, NC, USA) and WinSQL (Synametrics, Plainsboro, NJ, USA).

\section{Results}

\section{Sample description}

During the index hospital stay, a total of 866 patients initiated arformoterol and met all of the inclusion criteria. These patients were matched $(1: 2)$ on age, sex, APR-DRG severity of illness class, and primary COPD diagnosis with 1,732 patients treated with a nebulized SABA (Figure 1). During the index hospital stay, 135 patients died (54 [6.2\%] arformoterol 
and 81 [4.7\%] nebulized SABA patients) and could not be included in the readmission analysis, leaving a final sample of 812 arformoterol and 1,651 nebulized SABA patients. Among patients who died during the initial hospital admission, arformoterol patients were significantly more likely to have intensive care admissions compared with nebulized SABA patients ( $85 \%$ versus $51 \%$ ), which was a significant predictor of mortality (data not shown). Almost all patients (99.2\%) with intensive care admissions in the arformoterol cohort had this event prior to or concurrent with their treatment initiation with arformoterol.

Age, sex, APR-DRG severity of illness classes, and primary COPD diagnosis were nearly identical between the cohorts because the patients were matched on these characteristics. However, significant differences between patients treated with arformoterol and those treated with a nebulized SABA were observed on other demographic, hospital, clinical, and initial admission treatment characteristics (Table 1). Notably, arformoterol appeared to be selected for patients with a more severe symptom profile based on greater intensive care $(32.1 \%$ versus $18.4 \%, P<0.001)$, oxygen therapy $(78.0 \%$ versus $71.3 \%$, $P<0.001)$, and corticosteroid treatment $(87.2 \%$ versus $77.1 \%, P<0.001)$.

\section{Readmissions}

Seventy-one $(8.7 \%)$ of the arformoterol patients and $197(11.9 \%)$ of the nebulized SABA patients were readmitted to the same hospital within 30 days of their index discharge $(P=0.016)$. The unadjusted 30 -day readmission rates for the two cohorts varied by APR-DRG severity class (Figure 2 ), with significantly fewer readmissions among patients treated with arformoterol in the major $(8.1 \%$ versus $12.6 \%, P=0.031)$ and extreme $(9.9 \%$ versus $17.5 \%, P=0.028)$ severity categories.

A multivariate logistic regression was used to estimate the odds of 30-day readmission between the arformoterol and nebulized SABA groups, after adjusting for covariates of sex, age, race, hospital characteristics, diagnoses, admission, treatment, length of stay, and severity of illness. After adjusting for initial admission differences, the odds for readmission were $31 \%$ lower (odds ratio $0.69 ; 95 \%$ confidence interval 0.51-0.92) for patients treated with arformoterol than for patients treated only with a nebulized SABA. Patients with APR-DRG major (odds ratio $1.89, P=0.042$ ) and extreme (odds ratio $2.49, P=0.007$ ) severity classes during the index hospital stay were significantly more likely to be readmitted to the hospital within 30 days (Table 2).
Table I Characteristics of arformoterol and nebulized SABA patients during initial hospitalization

\begin{tabular}{|c|c|c|c|}
\hline \multirow[t]{2}{*}{ Variable } & \multirow{2}{*}{$\begin{array}{l}\text { Arformoterol } \\
(n=8 \mid 2) \\
M \pm S D \text { or } \\
n(\%)\end{array}$} & \multirow{2}{*}{$\begin{array}{l}\begin{array}{l}\text { Nebulized } \\
\text { SABA } \\
(n=I, 65 I)\end{array} \\
M \pm \text { SD or } \\
n(\%)\end{array}$} & \multirow[t]{2}{*}{$P$-value } \\
\hline & & & \\
\hline Age, years & $68.6 \pm 10.6$ & $68.6 \pm 10.6$ & 0.877 \\
\hline \multicolumn{4}{|l|}{ Age group } \\
\hline $40-54$ years & $86(10.6 \%)$ & 177 (10.7\%) & 0.922 \\
\hline $55-64$ years & $186(22.9 \%)$ & 374 (22.7\%) & 0.888 \\
\hline $65-74$ years & $290(35.7 \%)$ & $595(36.0 \%)$ & 0.875 \\
\hline $75+$ years & $250(30.8 \%)$ & 505 (30.6\%) & 0.919 \\
\hline Female sex & $463(57.0 \%)$ & $946(57.3 \%)$ & 0.895 \\
\hline Caucasian race & $678(83.5 \%)$ & I,I 66 (70.6\%) & $<0.001$ \\
\hline \multicolumn{4}{|l|}{ Geographic location } \\
\hline Midwest & 248 (30.5\%) & 278 (16.8\%) & $<0.001$ \\
\hline South & 477 (58.7\%) & 835 (50.6\%) & $<0.001$ \\
\hline Northeast & 57 (7.0\%) & 189 (11.4\%) & $<0.001$ \\
\hline West & $30(3.7 \%)$ & $349(21.1 \%)$ & $<0.001$ \\
\hline Rural hospital & $182(22.4 \%)$ & $284(17.2 \%)$ & 0.002 \\
\hline Emergency admission & $692(85.2 \%)$ & I,5 0 (9l.5\%) & $<0.001$ \\
\hline $\begin{array}{l}\text { ICU care for at least } \\
\text { one day }\end{array}$ & $26 \mid(32.1 \%)$ & $304(18.4 \%)$ & $<0.001$ \\
\hline \multicolumn{4}{|l|}{ APR-DRG severity } \\
\hline \multicolumn{4}{|l|}{ of illness } \\
\hline Minor & $68(8.5 \%)$ & I 37 (8.3\%) & 0.867 \\
\hline Moderate & $237(29.2 \%)$ & $483(29.3 \%)$ & 0.972 \\
\hline Major & 345 (42.5\%) & 699 (42.3\%) & 0.944 \\
\hline Extreme & 161 (19.8\%) & $332(20.1 \%)$ & 0.870 \\
\hline \multicolumn{4}{|l|}{ Therapy } \\
\hline Respiratory therapy & 800 (98.5\%) & $\mathrm{I}, 60 \mathrm{I}(97.0 \%)$ & 0.021 \\
\hline $\begin{array}{l}\text { Oxygen saturation } \\
\text { test }\end{array}$ & $523(64.4 \%)$ & $930(56.3 \%)$ & 0.001 \\
\hline Oxygen therapy & $633(78.0 \%)$ & I, I 77 (7I.3\%) & $<0.001$ \\
\hline \multicolumn{4}{|l|}{ Non- $\beta_{2}$ agonists } \\
\hline Anticholinergics & $624(76.8 \%)$ & I,236 (74.9\%) & 0.282 \\
\hline Corticosteroids & 708 (87.2\%) & I,273 (77.1\%) & $<0.001$ \\
\hline Antibiotics & 707 (87.1\%) & I,470 (89.0\%) & 0.152 \\
\hline Other & $4(0.5 \%)$ & $21(1.3 \%)$ & 0.070 \\
\hline
\end{tabular}

Notes: Differences in mean age was evaluated using a $t$-test. Differences on the categorical variables were evaluated using chi-square tests.

Abbreviations: APR-DRG, 3M ${ }^{\mathrm{TM}}$ All Patient Refined ${ }^{\mathrm{TM}}$-Diagnosis Related Groups; $M$, mean; SABA, nebulized short-acting $\beta_{2}$ agonist; SD, standard deviation; ICU, intensive care unit.

\section{Discussion}

In this retrospective observational study of usual clinical care, patients treated with nebulized arformoterol, had significantly lower (8.7\% versus $11.9 \%$ ) 30-day readmissions compared with patients receiving nebulized SABA treatment. Despite baseline differences in intensive care stays and oxygen use suggesting that the arformoterol patients were more severe, patients treated with arformoterol had significantly lower adjusted odds (odds ratio 0.69) of being readmitted 


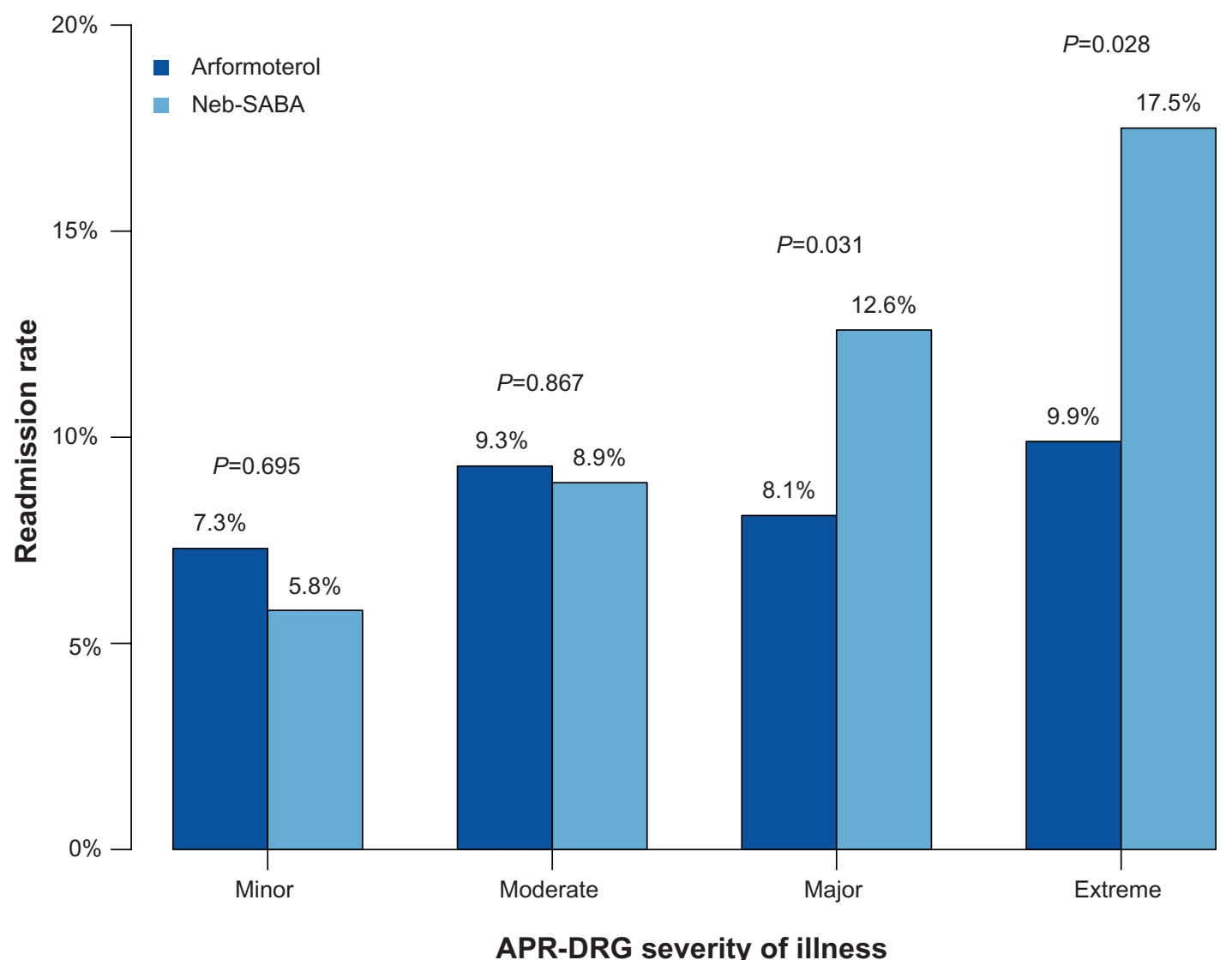

Figure 2 Unadjusted all-cause 30-day readmission rates for arformoterol-treated and nebulized SABA-treated patients by APR-DRG severity.

Notes: Unadjusted comparisons within each APR-DRG severity class were completed using chi-square tests. In the multivariate logistic regression that adjusted for initial admission differences, the odds for readmission were $31 \%$ lower (odds ratio $0.69,95 \%$ confidence interval $0.5 \mathrm{I}-0.92$ ) for patients treated with arformoterol than for patients treated only with neb-SABA.

Abbreviations: APR-DRG, 3M ${ }^{\mathrm{TM}}$ All Patient Refined ${ }^{\mathrm{TM}}$-Diagnosis Related Groups; neb-SABA, nebulized short-acting $\beta_{2}$ agonist.

within 30 days of discharge than matched patients treated with a nebulized SABA. The reduced 30-day readmission rates for arformoterol-treated patients, despite poor baseline status, suggests that those treated with arformoterol may have better stabilization status at discharge. Further investigations into discharge status and consequent outcomes post-discharge are needed. Future research using prospectively collected data, rather than retrospective data, can also examine any additional hospital factors, such as discharge planning, device training, and patient education, which may contribute to the differences in 30-day readmission observed in this study.

The 30-day readmission rates observed in this study were lower compared with the recent literature. ${ }^{10}$ This difference may be explained by the younger patient mix in this study; a third of patients were below 65 years of age, whereas the other study focused solely on Medicare beneficiaries. Consistent with the literature findings, patients with higher APR-DRG severity were more likely to be readmitted than patients with lower severity in our study. Interestingly, the unadjusted dif- ference in readmission rates between the arformoterol and nebulized SABA cohorts was most pronounced among the patients with major or extreme APR-DRG severity scores. While the sample size was too small to conduct inferential analysis, additional studies comparing outcomes between arformoterol and use of other agents may shed light on the role of arformoterol in severely compromised exacerbating COPD patients.

A previous meta-analysis of randomized controlled trials in COPD found that LABA treatment reduced exacerbations relative to placebo by $21 \% ;{ }^{24}$ however, there is a paucity of randomized controlled trials comparing the rates of exacerbations or hospitalizations between LABA and SABA treatments. ${ }^{25}$ Two previously published, retrospective outpatient studies had similar findings. A retrospective study of usual care in Scotland found that outpatients treated with LABAs had reduced rates of hospitalization relative to outpatients treated with only SABAs or antimuscarinic agents. ${ }^{18}$ Using electronic health records, another study comparing 
Table 2 Logistic regression model

\begin{tabular}{|c|c|c|c|c|c|}
\hline \multirow{2}{*}{$\begin{array}{l}\text { Variable } \\
\text { Arformoterol } \\
\text { treatment }\end{array}$} & \multirow{2}{*}{$\begin{array}{l}\text { Estimate } \\
-0.377\end{array}$} & \multirow{2}{*}{$\begin{array}{l}\text { OR } \\
0.686\end{array}$} & \multicolumn{2}{|c|}{$95 \% \mathrm{Cl}$} & \multirow{2}{*}{$\begin{array}{l}P \text {-value } \\
0.012\end{array}$} \\
\hline & & & $0.5 \mathrm{II}$ & 0.920 & \\
\hline Female sex & -0.077 & 0.858 & 0.663 & I.II & 0.244 \\
\hline \multicolumn{6}{|l|}{ Age group } \\
\hline $40-50$ years & -0.050 & 0.870 & 0.457 & 1.656 & 0.821 \\
\hline $5 I-60$ years & -0.039 & 0.879 & 0.617 & 1.252 & 0.800 \\
\hline Nonwhite race & 0.044 & 1.092 & 0.814 & 1.465 & 0.557 \\
\hline Rural hospital & 0.034 & 1.070 & 0.75 & 1.525 & 0.710 \\
\hline Teaching hospital & 0.152 & 1.164 & 0.865 & 1.566 & 0.317 \\
\hline Total hospital beds, $\mathrm{n}$ & 0.00017 & 1.000 & 0.999 & 1.001 & $0.64 I$ \\
\hline $\begin{array}{l}\text { Primary diagnosis } \\
\text { of COPD }\end{array}$ & 0.191 & 1.210 & 0.912 & 1.606 & 0.186 \\
\hline Emergency admission & 0.058 & 1.123 & 0.827 & 1.526 & 0.457 \\
\hline Length of stay, days & 0.016 & 1.016 & 0.999 & 1.033 & 0.065 \\
\hline \multicolumn{6}{|l|}{$\begin{array}{l}\text { APR-DRG severity } \\
\text { of illness }\end{array}$} \\
\hline Moderate & 0.433 & 1.542 & 0.823 & 2.886 & 0.176 \\
\hline Major & 0.637 & 1.890 & 1.023 & 3.491 & 0.042 \\
\hline Extreme & 0.911 & 2.487 & 1.276 & 4.846 & 0.007 \\
\hline Oxygen therapy & -0.030 & 0.970 & 0.713 & 1.321 & 0.848 \\
\hline Respiratory therapy & -0.171 & 0.843 & 0.371 & 1.914 & 0.682 \\
\hline Anticholinergic use & -0.136 & 0.873 & 0.649 & 1.175 & 0.370 \\
\hline Corticosteroid use & 0.251 & 1.286 & 0.905 & 1.826 & 0.160 \\
\hline Antibiotic use & 0.109 & 1.115 & 0.794 & 1.564 & 0.530 \\
\hline Intercept & -2.907 & & & & $<0.001$ \\
\hline
\end{tabular}

Abbreviations: APR-DRG, 3M ${ }^{\mathrm{TM}}$ All Patient Refined ${ }^{\mathrm{TM}}$-Diagnosis Related Groups; $\mathrm{Cl}$, confidence interval; OR, odds ratio; COPD, chronic obstructive pulmonary disease.

patients treated with LABA and inhaled corticosteroids with patients treated with SABA and inhaled corticosteroid recipients also found reduced readmissions for the LABA-treated and inhaled corticosteroid-treated cohort. ${ }^{26}$ The findings of this study are consistent with prior research and treatment guidelines recommending the use of long-acting rather than short-acting bronchodilators for maintenance treatment in patients with moderate to severe COPD. ${ }^{16}$ Our finding that initiating hospitalized patients (once admitted) with COPD on arformoterol rather than a nebulized SABA have lower 30-day readmissions appears to be an important and unique contribution to the literature.

Reducing 30-day readmissions among patients with COPD has important implications for hospitals since the Patient Protection and Affordability Care Act has authorized the CMS to reduce hospital payments for hospitals with excessive rates of 30-day readmissions. ${ }^{11,12}$ Debate about this pay for performance program is ongoing, including questions regarding the incentive size and structure, ${ }^{27}$ the focus on 30-day readmissions rather than broader clinical outcomes, ${ }^{28}$ and the potential for sharing risks and reward among all entities in the community responsible for improving care. ${ }^{29}$ The program will begin to target COPD patients at high risk for readmission within 30 days ${ }^{10}$ beginning in the fall of $2014 .{ }^{11}$ These study results suggest that hospitals with excess 30-day readmission rates for COPD may want to consider quality improvement initiatives that encourage the use of LABA instead of SABA when appropriate, ${ }^{16}$ and may also want to consider including such agents on their formularies that add intrinsic value through an impact on hospital readmissions.

An examination of the average annual costs of treating COPD in the US in 2006 revealed that the average patient incurred $\$ 3,943$ in direct expenses, but those who were hospitalized incurred $\$ 15,093$, and those requiring treatment in the intensive care unit during hospitalization incurred $\$ 43,471 .^{5}$ Although most COPD patients are not hospitalized in a given year, inpatient costs are the largest driver of direct health care costs. ${ }^{7}$ In the current analysis, the difference in readmission rates between arformoterol and nebulized SABA was most pronounced for patients with a more severe illness profile. Initiating patients on a nebulized LABA, such as arformoterol, instead of using nebulized SABAs alone during an inpatient admission for COPD could reduce health care costs by preventing expensive readmissions. Decreasing readmission rates may also lead to better patient outcomes by potentially preventing a decline in lung function ${ }^{8}$ and reduction in quality of life. ${ }^{30}$

\section{Limitations}

The administrative hospital data used in this study were originally collected for clinical and economic benchmarking rather than research purposes. Therefore, the information may not be as precise as prospectively collected clinical research data. Patients with COPD discharge diagnoses in the hospital were assumed to have met formal COPD diagnostic criteria, but no spirometry results were available to confirm the diagnoses. Although the analyses controlled for a large number of background characteristics, the data were limited in scope. Some important measures of severity in COPD, such as measures of lung function, smoking status, and medication treatment outside of the hospital, were not available and may have differed between patients treated with arformoterol or a nebulized SABA. However, the arformoterol group had greater intensive care unit use during the baseline admission, suggesting that the selection bias for this cohort was to have more severe patients who were more likely, rather than less likely, to be readmitted. Readmissions to hospitals, other than the one with 
the index admission, were not captured in the data, potentially resulting in underestimation of the 30-day readmission rates. Cohorts were not matched on hospital, so hospital represents an uncontrolled variable. Finally, variations in treatment and discharge protocol between hospital admissions could not be controlled for in this study due to the absence of such information and small sample sizes precluded the use of institution as a matching variable. Prospective, interventional research that compares the rates of hospital readmission for patients with COPD randomized to arformoterol or a nebulized SABA may be warranted to confirm these findings.

\section{Conclusion}

This retrospective comparative study of the nebulized LABA, arformoterol, versus nebulized SABAs found that patients treated with arformoterol had significantly reduced odds of all-cause 30-day hospital readmissions relative to matched patients treated with SABAs. Initiating hospitalized COPD patients with a LABA instead of a SABA may help prevent all-cause readmissions, reduce health care costs, and prevent greater deterioration in lung function, particularly among patients with a more severe illness profile.

\section{Acknowledgments}

The authors would like to acknowledge Bernadette Johnson of Premier Healthcare solutions, Inc. for her analytical support, and Michael D Stensland of Agile Outcomes Research, Inc. for his technical writing support.

\section{Disclosure}

$\mathrm{VB}, \mathrm{JK}$, and KR are all full-time employees of Sunovion Pharmaceuticals, Inc., the study sponsor. SBR and FRE are employees of Premier Healthcare solutions, Inc., which contracted with Sunovion Pharmaceuticals, Inc. to conduct this research. SSB reports no financial interests in this work.

\section{References}

1. Halbert RJ, Natoli JL, Gano A, Badamgarav E, Buist AS, Mannino DM. Global burden of COPD: systematic review and metaanalysis. Eur Respir J. 2006;28(3):523-532.

2. Mathers C, Boerma T, Fat DM. The Global Burden of Disease: 2004 Update. Geneva, Switzerland: World Health Organization; 2008.

3. National Heart Lung and Blood Institute. Morbidity and Mortaility: 2012 Chart Bood on Cardiovascular, Lung, and Blood Diseases. 2012. Available from: http://www.nhlbi.nih.gov/resources/docs/cht-book.htm. Accessed August 1, 2013.

4. Camilli AE, Robbins DR, Lebowitz MD. Death certificate reporting of confirmed airways obstructive disease. Am J Epidemiol. 1991;133(8): 795-800.

5. Dalal AA, Christensen L, Liu F, Riedel AA. Direct costs of chronic obstructive pulmonary disease among managed care patients. Int JChron Obstruct Pulmon Dis. 2010;5:341-349.
6. Hilleman DE, Dewan N, Malesker M, Friedman M. Pharmacoeconomic evaluation of COPD. 2000. Chest. 2009;136 Suppl 5:e30.

7. Strassels SA, Smith DH, Sullivan SD, Mahajan PS. The costs of treating COPD in the United States. Chest. 2001;119(2):344-352.

8. Donaldson GC, Seemungal TAR, Bhowmik A, Wedzicha JA. Relationship between exacerbation frequency and lung function decline in chronic obstructive pulmonary disease. Thorax. 2002;57(10):847-852.

9. Suissa S, Dell'aniello S, Ernst P. Long-term natural history of chronic obstructive pulmonary disease: severe exacerbations and mortality. Thorax. 2012;67(11):957-963.

10. Jencks SF, Williams MV, Coleman EA. Rehospitalizations among patients in the Medicare fee-for-service program. $N$ Engl $J$ Med. 2009;360(14):1418-1428.

11. Medicare Payment Advisory Commission. Report to Congress: Promoting Greater Efficiency in Medicare. 2007. Available from: http://www.medpac.gov/documents/jun07_entirereport.pdf. Accessed August 1, 2013.

12. United States Congress. Patient Protection and Affordable Care Act. 2010. Available from: http://www.gpo.gov/fdsys/pkg/PLAW111publ148/pdf/PLAW-111publ148.pdf. Accessed August 1, 2013.

13. Williams MV. A requirement to reduce readmissions: take care of the patient, not just the disease. JAMA. 2013;309(4):394-396.

14. Dharmarajan K, Hsieh AF, Lin Z, et al. Diagnoses and timing of 30-day readmissions after hospitalization for heart failure, acute myocardial infarction, or pneumonia. JAMA. 2013;309(4):355-363.

15. Brock J, Mitchell J, Irby K, et al. Association between quality improvement for care transitions in communities and rehospitalizations among Medicare beneficiaries. JAMA. 2013;309(4):381-391.

16. Global Initiative for Chronic Obstructive Lung Disease. Global Strategy for the Diagnosis, Management, and Prevention of COPD (Updated 2013). 2013. Available from: http://www.goldcopd.org/guidelinesglobal-strategy-for-diagnosis-management.html. Accessed August 1, 2013.

17. Fitch K, Iwasaki K, Pyenson B, Plauschinat C, Zhang J. Variation in adherence with Global Initiative for Chronic Obstructive Lung Disease (GOLD) drug therapy guidelines: a retrospective actuarial claims data analysis. Curr Med Res Opin. 2011;27(7):1425-1429.

18. Short PM, Lipworth SIW, Elder DHJ, Schembri S, Lipworth BJ. Effect of beta blockers in treatment of chronic obstructive pulmonary disease: a retrospective cohort study. $B M J$. 2011;342:d2549.

19. Geller DE. Comparing clinical features of the nebulizer, metereddose inhaler, and dry powder inhaler. Respir Care. 2005;50(10): 1313-1321.

20. Dhand R, Dolovich M, Chipps B, Myers TR, Restrepo R, Farrar JR. The role of nebulized therapy in the management of COPD: evidence and recommendations. COPD. 2012;9(1):58-72.

21. United States Congress. Health Insurance Portability and Accountability Act of 1996. 1996. Available from: http://www.gpo.gov/fdsys/ pkg/PLAW-104publ191/html/PLAW-104publ191.htm. Accessed September 19, 2012.

22. Kirby SE, Dennis SM, Jayasinghe UW, Harris MF. Patient related factors in frequent readmissions: the influence of condition, access to services and patient choice. BMC Health Serv Res. 2010;10:216.

23. Averill RF, Goldfield N, Hughes JS, et al. All Patient Refined Diagnosis Related Groups (APR-DRGs), Version 20.0: Methodology Overview. 2003. Available from: http://www.hcup-us.ahrq.gov. Accessed June 20, 2012.

24. Rodrigo GJ, Nannini LJ, Rodríguez-Roisin R. Safety of long-acting beta-agonists in stable COPD: a systematic review. Chest. 2008;133(5): 1079-1087.

25. Bollu VK, Karafilidis J, Colosia A, Bennett L, Hanania N. Comparison of efficacy and safety outcomes in randomized trials of long-acting and short-acting $\beta 2$-agonists for chronic obstructive pulmonary disease: a review. J Pulmon Resp Med. 2013;3(1):137.

26. Kiri VA, Bettoncelli G, Testi R, Viegi G. Inhaled corticosteroids are more effective in COPD patients when used with LABA than with SABA. Respir Med. 2005;99(9):1115-1124. 
27. Jha AK. Time to get serious about pay for performance. JAMA. 2013;309(4):347-348.

28. Vaduganathan M, Bonow RO, Gheorghiade M. Thirty-day readmissions: the clock is ticking. JAMA. 2013;309(4):345-346.

29. McCarthy D, Johnson MB, Audet A-M. Recasting readmissions by placing the hospital role in community context. JAMA. 2013;309(4): 351-352.
30. Llor C, Molina J, Naberan K, Cots JM, Ros F, Miravitlles M. Exacerbations worsen the quality of life of chronic obstructive pulmonary disease patients in primary health care. Int J Clin Pract. 2008;62(4): $585-592$.

International Journal of COPD

\section{Publish your work in this journal}

The International Journal of COPD is an international, peer-reviewed journal of therapeutics and pharmacology focusing on concise rapid reporting of clinical studies and reviews in COPD. Special focus is given to the pathophysiological processes underlying the disease, intervention programs, patient focused education, and self management protocols.

\section{Dovepress}

This journal is indexed on PubMed Central, MedLine and CAS. The manuscript management system is completely online and includes a very quick and fair peer-review system, which is all easy to use. Visit $\mathrm{http}: / /$ www.dovepress.com/testimonials.php to read real quotes from published authors.

Submit your manuscript here: http://www.dovepress.com/international-journal-of-copd-journal 